\title{
Self-reported advertising exposure to sugar-sweetened beverages among US youth
}

\author{
Gayathri Kumar*, Stephen Onufrak, Deena Zytnick, Beverly Kingsley and Sohyun Park \\ Division of Nutrition, Physical Activity and Obesity, National Center for Chronic Disease Prevention and Health \\ Promotion, Centers for Disease Control and Prevention, 4771 Buford Highway, Atlanta, GA 30341, USA
}

Submitted 9 August 2013: Final revision received 13 June 2014: Accepted 10 July 2014: First published online 28 August 2014

\begin{abstract}
Objective: According to the Federal Trade Commission, in 2009, the top food category with teen-directed marketing expenditures was sugar-sweetened beverages (SSB). The present study reports on exposure to SSB advertisements using self-report data from adolescents.

Design: Cross-sectional study design using descriptive statistics to assess selfreported frequency of exposure to SSB advertisements and multivariable logistic regression to examine associations between frequency of SSB advertising exposure and sociodemographic variables.

Setting: Online survey conducted at home.

Subjects: US adolescents aged $12-17$ years ( $n$ 847).

Results: Among the surveyed adolescents, $42 \%$ to $54 \%$ reported seeing/hearing SSB advertisements $\geq 1$ time/d. Those aged $14-15$ years were more likely to report seeing/hearing soda, sports drink and energy drink advertisements $\geq 1$ time/d than 16- to 17-year-olds. Males were more likely to report seeing/hearing sports drink advertising $\geq 1$ time/d than females. Non-Hispanic black adolescents were more likely to report seeing/hearing fruit drink and sports drink advertisements $\geq 1$ time/d than non-Hispanic white adolescents. Adolescents whose parents had high-school education or less were more likely to report seeing/hearing soda, fruit drink and energy drink advertisements $\geq 1$ time/d than adolescents whose parents were college graduates.

Conclusions: Almost half of the adolescents sampled reported daily SSB advertising exposure, with higher exposure among African Americans and adolescents with less educated parents. These data can help inform potential actions that decision makers might take, such as education of adolescents and their caregivers on the potential impact of beverage advertising, especially among groups at higher risk for obesity.
\end{abstract}

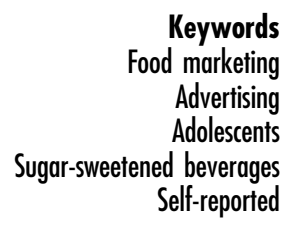

Approximately nine out of ten advertised foods viewed by adolescents (aged 12-17 years) are high in fat, added sugars or sodium ${ }^{(1)}$. According to the Federal Trade Commission, in 2009, \$US 1.79 billion was spent on marketing of food products to youth and the top three food categories with teen-directed marketing exposures were sugar-sweetened beverages (SSB; 38\%), quickservice restaurants $(18 \%)$ and breakfast cereals $(10 \%)^{(2)}$. In the present paper, SSB are liquids sweetened with various forms of added sugars that add energy and include, but are not limited to, soda, fruit ades and fruit drinks, and sports and energy drinks ${ }^{(3)}$.

Although SSB were the top food category in terms of teen-directed marketing expenditures in 2009, it is unclear how often adolescents are exposed to food and beverage marketing. Although literature on SSB advertising exposure by adolescents exists, the literature predominantly focuses on television ratings data from Nielsen Media Research $^{(1,4)}$. There is still a need to characterize overall marketing exposure to SSB in adolescents, especially given that SSB are the largest single contributor of added sugars to the US diet with adolescents aged 12-19 years being the highest consumers of $\mathrm{SSB}^{(5)}$. Determining adolescents' overall level of food/beverage marketing exposure is challenging, because there is no simple method to assess overall marketing exposure that occurs outside measured media, such as in-store displays, social media or mobile apps. The Yale Rudd Center conducted in-depth content analyses of various modes of SSB marketing exposure targeting children and adolescents, including social 
media marketing and banner advertising, and showed that many SSB companies promoted their products on youth websites and in a way to appeal to youth audiences ${ }^{(6)}$. However, assessing overall marketing exposure via all possible types of media in a given time period can be more challenging since adolescents may have varying levels of exposure through these different media. One way to possibly assess overall beverage marketing exposure is to survey adolescents. To date, we have found no literature on US adolescent-reported overall exposure to advertising of SSB and which adolescent sub-populations are more likely to be exposed to SSB advertisements using such data. While previous research has shown that certain adolescent sub-populations may be targeted for certain food/beverage advertisements, such as non-Hispanic black adolescents for fast food and SSB advertisements ${ }^{(1,6)}$, it would be valuable to understand if adolescents also perceive these advertisements. Such research can help to identify which sub-populations may benefit from more targeted intervention efforts, such as education of adolescents and their caregivers on the potential impact of beverage advertising. In the present study, we examined: (i) the prevalence of overall self-reported exposure to soda, fruit drink, sports drink and energy drink advertisements; and (ii) the sociodemographic characteristics associated with overall self-reported exposure to soda, fruit drink, sports drink and energy drink advertisements. These four beverages were chosen for inclusion in the questionnaire for the following two reasons: (i) they were the beverages that had the highest advertising spending in $2010^{(6)}$; and (ii) they are the most commonly consumed SSB among youth ${ }^{(7)}$.

\section{Methods}

\section{Sample and survey administration}

This descriptive study used Porter Novelli's (a public relations agency) 2012 Summer ConsumerStyles and YouthStyles surveys, an online survey of US adolescents aged 12-17 years, which was designed to assess health beliefs and behaviours surrounding important public health concerns. Participants include the children of adult participants who completed the ConsumerStyles Survey (administered in three parts: Spring ConsumerStyles Survey, Summer ConsumerStyles Survey and Fall ConsumerStyles Survey in 2012), which is administered by Knowledge Networks, an online research firm that recruited an online research panel to provide a convenience sample of approximately 50000 panellists.

The YouthStyles survey sample was obtained as detailed below. First, the Spring ConsumerStyles survey was originally sent to a sample of 11636 adult (aged 18 years and older) panellists from the original 50000 panellists, of whom 6728 participants completed (response rate $58 \%$ ). From these 6728 adult participants who completed the SpringStyles survey, those adult panellists with children aged $12-17$ years
( $n$ 1648) were sent the SummerStyles survey. Children of these 1648 adult panellists were sent the YouthStyles survey, which a total of 847 adolescents completed (response rate $51 \%$ ). Respondents were excluded if they answered 'don't know' or 'refused' to the questions that were analysed in this survey (discussed further below). This led to final analytic samples of 726 for soda advertising, 694 for fruit drinks, 715 for sports drinks and 695 for energy drinks.

Using $\chi^{2}$ analyses, we found no significant differences by sociodemographic characteristics between the adolescents who were included in the study and the adolescents excluded from the study for each of the SSB advertising categories. YouthStyles participants are assigned sample weights to match the sample to the 2012 US Census Bureau's Current Population Survey ${ }^{(8)}$. The weighted YouthStyles demographic data are comparable to the 2012 US Current Population Survey estimates (data not shown). The survey went through Porter Novelli's Institutional Review Board process but was exempt from the Centers for Disease Control and Prevention's Institutional Review Board process because personal identifiers were not included in the data provided to the Centers for Disease Control and Prevention.

\section{Advertising exposure to sugar-sweetened beverages}

The outcome of interest was self-reported frequency of advertising exposure for each of the following four SSB: (i) 'Soda (i.e. Coke ${ }^{\mathrm{TM}}$, Sprite ${ }^{\mathrm{TM}}$, Mountain $\left.\mathrm{Dew}^{\mathrm{TM}}\right)^{(1)}$; (ii) 'Fruit drinks (i.e. Capri Sun ${ }^{\mathrm{TM}}$, Sunny Delight ${ }^{\mathrm{TM}}$, Hawaiian Punch $^{\mathrm{TM}}$ '); (iii) 'Sports drinks (i.e. Gatorade ${ }^{\mathrm{TM}}$ or PowerAde $^{\mathrm{TM}}$ )'; and (iv) 'Energy drinks (i.e. Red Bull ${ }^{\mathrm{TM}}$, 5-h Energy $^{\mathrm{TM}}$, NOS $\left.{ }^{\mathrm{TM}}\right)^{\prime}$. Advertising exposure for these drinks was based on the following question: 'During a typical week, how often do you see or hear advertisements for each of the following?' Response options for each SSB type were $<1$ time/week, 1-6 times/week, 1 time/d, multiple times daily and don't know. For the bivariate analysis, three mutually exclusive outcome categories were created: $<1$ time/week, 1-6 times/week and $\geq 1$ time/d.

\section{Sociodemographic variables}

Sociodemographic variables from YouthStyles included age (12-13, 14-15 and 16-17 years), sex, race/ethnicity (non-Hispanic white, non-Hispanic black, Hispanic and other/multiracial), parent education level as reported in HealthStyles (high school or less, some college and college graduate), family annual income ( $\leq$ \$US 34999 , \$US 35 000-74 999, \$US 75 000-99 999 and $\geq$ \$US 100 000) and geographic region (Northeast, Midwest, South and West).

\section{Statistical analysis}

For the bivariate analysis, $\chi^{2}$ tests were used to examine the relationship between frequency of each SSB advertising exposure and sociodemographic variables, where the cut-off point for statistical significance was $P<0 \cdot 05$. Separate multivariate polytomous logistic regression models were fit 
to estimate adjusted odds ratios and $95 \%$ confidence intervals for daily ( $\geq 1$ time/d) and weekly (1-6 times/week) advertising exposure for each SSB type with the comparison group for the regression model being advertising exposure $<1$ time/week. The reference groups for each of the sociodemographic categories were chosen based on either the largest sample size (i.e. age and race/ethnicity) or the prevalence of SSB consumption observed among demographic subgroups (e.g. greater SSB consumption in adolescents from households with lower incomes) ${ }^{(9,10)}$.

All sociodemographic variables were included in each model. All statistical analyses were performed with the statistical software package SAS version 9.3 and incorporated appropriate procedures to account for the sample design.

\section{Results}

Approximately $54 \%, 42 \%, 46 \%$ and $42 \%$ of adolescents reported seeing/hearing advertisements for soda (Table 1), fruit drinks (Table 1), sports drinks (Table 2) and energy drinks (Table 2) $\geq 1$ time/d, respectively, while $22 \%$ of adolescents reported seeing advertisements for all four SSB $\geq 1$ time/d. The frequency with which different SSB advertisements were seen/heard differed by several sociodemographic characteristics (Tables 1 and $2, \chi^{2}$ tests, $P<0.05)$. Among groups where significant differences existed, the proportion of adolescents who viewed soda advertisements $\geq 1$ time/d was highest among adolescents whose parents had high-school education or less. The proportion of adolescents who viewed fruit drink advertisements $\geq 1$ time/d was highest among non-Hispanic blacks and those whose parents had high-school education or less. The proportion of adolescents who viewed sports drink advertisements $\geq 1$ time/d was highest among 14- to 15-year olds, males and non-Hispanic blacks. The proportion of adolescents who viewed energy drink advertisements $\geq 1$ time/d was highest among 14- to 15-year olds, adolescents whose parents had high-school education or less, adolescents from families with an annual family income of $\leq \$ 34999$ and adolescents from the Midwest region of the USA.

In the logistic regression analyses, some of these differences maintained. For soda advertising, 14- to 15-yearolds (OR $=2 \cdot 2 ; 95 \%$ CI 1.1, 4.2 v. 16- to 17-year-olds) and adolescents whose parents had high-school education or less $(\mathrm{OR}=2 \cdot 2 ; 95 \%$ CI 1.04, $4.7 v$. adolescents whose parents were college graduates) were more likely to report seeing/hearing advertisements one or more times daily (Table 1). For fruit drink advertising, non-Hispanic black adolescents ( $\mathrm{OR}=3.9 ; 95 \% \mathrm{CI} 1.5,10 \cdot 0 v$. white adolescents) and those whose parents had high-school education or less $(\mathrm{OR}=3 \cdot 1 ; 95 \% \mathrm{CI} 1 \cdot 5,6 \cdot 4 v$. those whose parents were college graduates) were more likely to report seeing/hearing advertisements one or more times daily (Table 1). For sports drink advertising, 14- to 15-year-olds ( $\mathrm{OR}=2.9 ; 95 \%$ CI $1.5,5.5 v$. 16- to 17 - year-olds), males
(OR $=1 \cdot 8 ; 95 \%$ CI 1.1, 3.1 $v$. females) and non-Hispanic black adolescents (OR $=4.0 ; 95 \%$ CI 1.5, 10.9; $v$. white adolescents) were more likely to report seeing/hearing advertisements one or more times daily (Table 2). For energy drink advertising, 14- to 15 -year-olds $(\mathrm{OR}=2 \cdot 2$; $95 \%$ CI $1.2,3.9 v$ v. 16- to 17 - year-olds) and adolescents whose parents had high-school education or less $(\mathrm{OR}=2 \cdot 6$; $95 \%$ CI 1.3, $5.4 v$. adolescents whose parents were college graduates) were more likely to report seeing/hearing advertisements one or more times daily (Table 2). There were no significant associations between household income or region of the USA and SSB advertising exposure. Odds ratios and confidence intervals are not reported for advertising exposure that was 1-6 times/week given that statistical significance in sociodemographic characteristics was not reached for soda, sports drink and energy drink advertising. However, for fruit drink advertising, 14- to 15-year-olds $(\mathrm{OR}=2.0 ; 95 \% \mathrm{CI} 1.04,3.95$ v. 16- to 17-year-olds) and adolescents whose parents had high-school education or less $(\mathrm{OR}=3 \cdot 4 ; 95 \%$ CI 1.6, 7.1 $v$. adolescents whose parents were college graduates) were more likely to report seeing/hearing advertisements 1-6 times/week, while adolescents from other/multiple races $(\mathrm{OR}=0.31 ; 95 \% \mathrm{CI} 0 \cdot 12,0.82 v$. white adolescents) were less likely to report seeing/hearing advertisements 1-6 times/week (data not shown).

\section{Discussion}

For each of four SSB types, more than $40 \%$ of adolescents reported seeing/hearing advertisements at least once daily. We also found significant differences in reported exposure according to age, sex, race/ethnicity and parent education level.

A greater proportion of adolescents reported seeing/ hearing advertisements for soda $\geq 1$ time/d than those who saw/heard advertisements for fruit drinks, sports drinks and energy drinks. In 2009, children and adolescents between the ages of 8 and 18 years averaged about $10 \cdot 5 \mathrm{~h}$ of total media exposure per day from a variety of media types including television, computer and print, with television continuing to remain the most commonly used media $^{(11)}$. In an era where adolescents' interaction with multiple types of media - including television, Internet and cell phone use - is increasing steadily ${ }^{(11)}$, it is not surprising yet concerning that the majority of adolescents reported seeing or hearing SSB advertisements at least once daily. Interestingly, according to a recent analysis by the Yale Rudd Center that used Nielsen ratings data to report adolescent exposure to food/beverage advertising on television commercials, adolescent exposure to regular and diet sodas averaged $2.5 \mathrm{ads} /$ week in $2011^{(4)}$, which is less than what the majority of adolescents report in the present analyses (54\% report viewing soda advertisements $\geq 1$ time/d). This difference could be explained by how the present study included self-reported exposures to all forms of marketing, not just television 
Table 1 Sociodemographic characteristics of adolescent respondents by frequency of soda and fruit drinks beverage advertising exposure: YouthStyles Survey, 2012*

\begin{tabular}{|c|c|c|c|c|c|c|c|c|c|c|c|c|c|c|c|c|c|c|c|}
\hline & & & & \multicolumn{8}{|c|}{ Soda $(n$ 726)† } & \multicolumn{8}{|c|}{ Fruit drinks ( $n$ 694)‡ } \\
\hline & & & & & & Bivaria & analysis & & & $\begin{array}{r}\mathrm{Mul} \\
\text { logistic }\end{array}$ & $\begin{array}{l}\text { ariable } \\
\text { gression§ }\end{array}$ & & & $\begin{array}{l}\text { Biva } \\
\text { anal }\end{array}$ & & & & $\begin{array}{r}M L \\
\text { logisti }\end{array}$ & $\begin{array}{l}\text { ivariable } \\
\text { regression§ }\end{array}$ \\
\hline & \multicolumn{3}{|c|}{ Total sample ( $n$ 847) } & \multicolumn{2}{|c|}{$<1$ time/week } & \multicolumn{2}{|c|}{ 1-6 times/week } & \multicolumn{2}{|c|}{$\geq 1$ time/d } & \multicolumn{2}{|c|}{$\geq 1$ time $/ \mathrm{d}$} & \multicolumn{2}{|c|}{$<1$ time/week } & \multicolumn{2}{|c|}{ 1-6 times/week } & \multicolumn{2}{|c|}{$\geq 1$ time/d } & \multicolumn{2}{|c|}{$\geq 1$ time $/ \mathrm{d}$} \\
\hline & $n$ & $\%$ & SE & $\%$ & SE & $\%$ & SE & $\%$ & SE & OR & $95 \% \mathrm{Cl}$ & $\%$ & SE & $\%$ & SE & $\%$ & $\mathrm{SE}$ & OR & $95 \% \mathrm{Cl}$ \\
\hline $\begin{array}{l}\text { Total sample } \\
\text { Age }\end{array}$ & & & & $17 \cdot 7$ & 1.9 & $28 \cdot 0$ & $2 \cdot 3$ & $54 \cdot 3$ & $2 \cdot 5$ & & & $29 \cdot 8$ & $2 \cdot 3$ & 28.5 & $2 \cdot 3$ & $41 \cdot 7$ & 2.5 & & \\
\hline $12-13$ years & 280 & 33.0 & $2 \cdot 2$ & $19 \cdot 2$ & 3.6 & $28 \cdot 2$ & 3.7 & $52 \cdot 6$ & $4 \cdot 4$ & 1.3 & $0.7,2.4$ & $27 \cdot 9$ & 3.8 & $27 \cdot 7$ & 3.8 & 44.5 & $4 \cdot 4$ & 1.5 & $0.8,2 \cdot 6$ \\
\hline $14-15$ years & 279 & $32 \cdot 9$ & $2 \cdot 2$ & $12 \cdot 3$ & $2 \cdot 6$ & $26 \cdot 7$ & 4.0 & $60 \cdot 9$ & 4.3 & $2 \cdot 2$ & $1 \cdot 1,4 \cdot 2$ & $25 \cdot 2$ & 3.8 & $33 \cdot 6$ & $4 \cdot 3$ & $41 \cdot 2$ & 4.4 & 1.5 & $0.8,2.9$ \\
\hline $16-17$ years & 290 & $34 \cdot 2$ & $2 \cdot 2$ & 21.4 & 3.6 & $29 \cdot 0$ & 4.0 & 49.7 & $4 \cdot 2$ & \multicolumn{2}{|c|}{ Reference } & $35 \cdot 9$ & 4.3 & $24 \cdot 3$ & 3.7 & 39.8 & 4.2 & \multicolumn{2}{|c|}{ Reference } \\
\hline \multicolumn{20}{|l|}{ Sex } \\
\hline Male & 431 & $50 \cdot 9$ & $2 \cdot 3$ & $17 \cdot 3$ & $2 \cdot 8$ & $27 \cdot 1$ & $3 \cdot 2$ & 55.6 & 3.5 & 1.2 & $0 \cdot 7,2 \cdot 1$ & $28 \cdot 9$ & $3 \cdot 2$ & $27 \cdot 2$ & 3.0 & 44.9 & 3.6 & 1.2 & $0.8,2 \cdot 0$ \\
\hline Female & 416 & $49 \cdot 1$ & $2 \cdot 3$ & $18 \cdot 2$ & $2 \cdot 7$ & 28.9 & $3 \cdot 2$ & $52 \cdot 9$ & 3.5 & \multicolumn{2}{|c|}{ Reference } & 31.6 & 3.3 & 29.9 & 3.5 & 38.5 & 3.4 & \multicolumn{2}{|c|}{ Reference } \\
\hline \multicolumn{20}{|l|}{ Race/ethnicity } \\
\hline White, non-Hispanic & 472 & $55 \cdot 7$ & $2 \cdot 4$ & $15 \cdot 9$ & $2 \cdot 1$ & $31 \cdot 2$ & $2 \cdot 8$ & $52 \cdot 9$ & 2.9 & \multicolumn{2}{|c|}{ Reference } & 32.5 & 2.8 & 31.5 & 2.8 & 40.0 & 2.9 & \multicolumn{2}{|c|}{ Reference } \\
\hline Black, non-Hispanic & 121 & $14 \cdot 3$ & 1.8 & $20 \cdot 8$ & 6.5 & $18 \cdot 1$ & $5 \cdot 8$ & $61 \cdot 1$ & $7 \cdot 6$ & 0.9 & $0.4,2 \cdot 0$ & 17.5 & $6 \cdot 1$ & 14.5 & 4.9 & 67.9 & $7 \cdot 3$ & 3.9 & $1.5,10.0$ \\
\hline Hispanic & 182 & 21.5 & $2 \cdot 2$ & $20 \cdot 1$ & $5 \cdot 3$ & 24.5 & $5 \cdot 7$ & 55.4 & 6.5 & 0.7 & $0.3,1.4$ & 24.2 & 5.7 & 34.1 & 6.4 & 41.8 & 6.2 & 1.4 & $0.7,2 \cdot 8$ \\
\hline Other/multiracial & 72 & 8.5 & 1.2 & $19 \cdot 0$ & $6 \cdot 2$ & 31.3 & 7.5 & $50 \cdot 0$ & 7.9 & 0.7 & $0.3,1.8$ & 45.4 & $8 \cdot 1$ & 14.7 & 4.4 & 39.9 & 8.1 & 0.7 & $0.3,1.7$ \\
\hline \multicolumn{20}{|l|}{ Parent education level } \\
\hline$\leq$ High school & 203 & $24 \cdot 0$ & $2 \cdot 1$ & 8.3 & $2 \cdot 1$ & $30 \cdot 7$ & $5 \cdot 2$ & 61.0 & $5 \cdot 3$ & $2 \cdot 2$ & $1 \cdot 0,4 \cdot 7$ & 14.6 & 2.9 & $35 \cdot 3$ & 5.7 & 50.1 & 5.7 & 3.1 & $1.5,6.4$ \\
\hline Some college & 302 & $35 \cdot 7$ & $2 \cdot 3$ & $24 \cdot 3$ & 4.0 & 24.8 & 3.6 & 51.0 & $4 \cdot 3$ & 0.6 & $0.4,1.2$ & 34.3 & $4 \cdot 1$ & 25.6 & 3.6 & $40 \cdot 1$ & 4.2 & 1.0 & $0.6,1.9$ \\
\hline$\geq$ College graduate & 342 & $40 \cdot 4$ & $2 \cdot 3$ & $17 \cdot 4$ & $2 \cdot 8$ & 29.2 & 3.4 & 53.4 & 3.7 & \multicolumn{2}{|c|}{ Reference } & $34 \cdot 3$ & 3.7 & 27.2 & $3 \cdot 2$ & 38.5 & 3.7 & \multicolumn{2}{|c|}{ Reference } \\
\hline \multicolumn{20}{|l|}{ Annual family income } \\
\hline$\leq \$ \cup S 34999$ & 224 & $26 \cdot 4$ & $2 \cdot 2$ & $13 \cdot 2$ & 3.7 & $26 \cdot 2$ & 5.1 & 60.5 & 5.5 & 1.5 & $0.7,3.6$ & $22 \cdot 9$ & 4.6 & $27 \cdot 7$ & $5 \cdot 3$ & $49 \cdot 4$ & $5 \cdot 6$ & 0.9 & $0.4,2.0$ \\
\hline \$US $35000-74999$ & 278 & $32 \cdot 8$ & $2 \cdot 1$ & $24 \cdot 6$ & 3.7 & $24 \cdot 2$ & 3.4 & $51 \cdot 2$ & $4 \cdot 2$ & 0.8 & $0.4,1.5$ & $36 \cdot 0$ & 4.0 & $26 \cdot 2$ & 3.5 & $37 \cdot 8$ & $4 \cdot 2$ & 0.5 & $0.3,1.0$ \\
\hline \$US $75000-99999$ & 158 & 18.6 & 1.8 & 11.2 & 3.3 & 31.6 & $5 \cdot 6$ & $57 \cdot 2$ & $5 \cdot 7$ & $2 \cdot 0$ & $0.9,4.5$ & $26 \cdot 6$ & $5 \cdot 2$ & $32 \cdot 0$ & 5.7 & 41.4 & $5 \cdot 7$ & 1.0 & $0.5,2.2$ \\
\hline$\geq \$$ US 100000 & 188 & $22 \cdot 2$ & 1.9 & $18 \cdot 1$ & $4 \cdot 1$ & $32 \cdot 8$ & $4 \cdot 3$ & 49.1 & $4 \cdot 8$ & \multicolumn{2}{|c|}{ Reference } & 30.9 & 4.7 & 29.8 & $4 \cdot 3$ & 39.3 & 4.9 & & ference \\
\hline Geographic region & & & & & & & & & & & & & & & & & & & \\
\hline Northeast & 145 & $17 \cdot 1$ & 1.8 & $15 \cdot 6$ & $5 \cdot 1$ & 34.2 & 5.9 & $50 \cdot 2$ & $6 \cdot 2$ & & rence & $23 \cdot 3$ & $5 \cdot 1$ & 37.8 & $6 \cdot 2$ & 38.9 & $6 \cdot 1$ & & ference \\
\hline Midwest & 185 & 21.9 & 1.9 & $17 \cdot 8$ & 3.5 & $32 \cdot 1$ & 4.5 & 50.2 & 4.8 & 1.0 & $0.4,2.6$ & 34.5 & $4 \cdot 8$ & $25 \cdot 8$ & 3.9 & 39.8 & 4.9 & 0.8 & $0.4,1.7$ \\
\hline South & 314 & $37 \cdot 1$ & $2 \cdot 3$ & $17 \cdot 6$ & $3 \cdot 4$ & 23.5 & 3.9 & 58.9 & 4.3 & 1.4 & $0.6,2 \cdot 6$ & $30 \cdot 9$ & $4 \cdot 1$ & $25 \cdot 7$ & 3.7 & $43 \cdot 3$ & $4 \cdot 2$ & 0.8 & $0.4,1.7$ \\
\hline West & 202 & 23.8 & $2 \cdot 0$ & $19 \cdot 4$ & 4.0 & $26 \cdot 3$ & $4 \cdot 2$ & $54 \cdot 3$ & $5 \cdot 0$ & 1.2 & $0.5,3.3$ & 28.5 & $4 \cdot 3$ & 28.0 & 4.9 & 43.5 & $5 \cdot 3$ & $1 \cdot 1$ & $0.5,2.4$ \\
\hline
\end{tabular}

SSB, sugar sweetened beverages.

S

Bolded italic values denote significant finding based on the $95 \% \mathrm{Cl}$ (i.e. the $95 \% \mathrm{Cl}$ does not include 1.0 ).

"Weighted percentage may not add up to $100 \%$ because of rounding. Data weighted to match the sample to the 2012 US Census Bureau's Current Population Survey.

†Frequency of exposure to soda (i.e. Coke ${ }^{\mathrm{TM}}$, Sprite $\mathrm{TM}$, Mountain Dew $\mathrm{w}^{\mathrm{TM}}$ ).

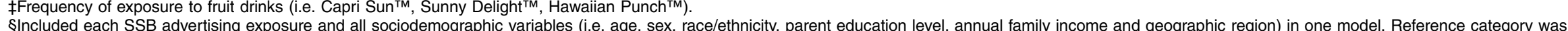

advertising exposure $<1$ time/week. 
Table 2 Sociodemographic characteristics of youth respondents by frequency of sports and energy drinks beverage advertising exposure: YouthStyles Survey, 2012*

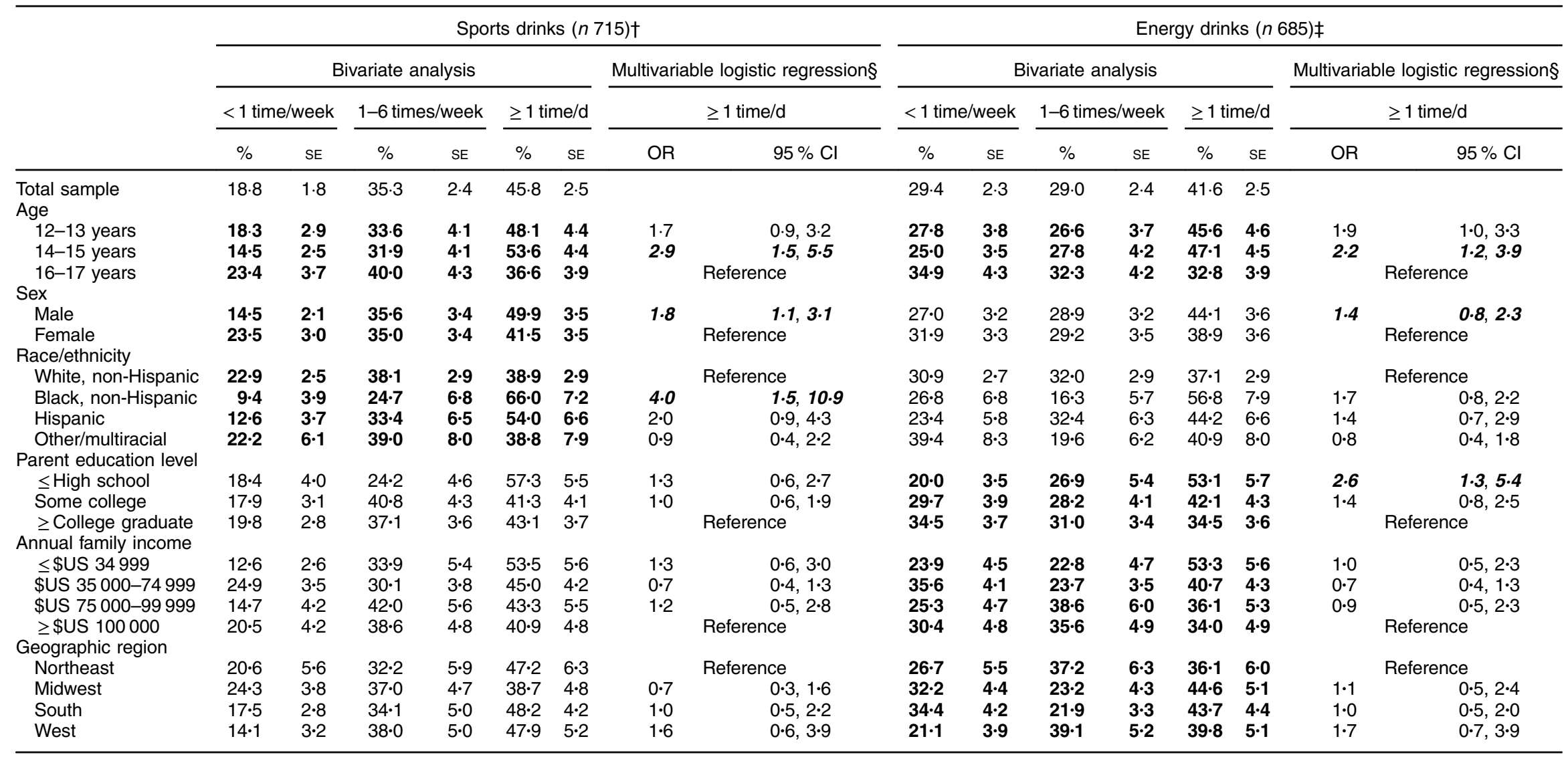

SSB, sugar-sweetened beverages.

Bolded values denote significance between SSB advertising exposure and sociodemographic characteristic with $X^{2}$ statistical significance at $P<0.05$.

Bolded italic values denote significant finding based on the $95 \% \mathrm{Cl}$ (i.e. the $95 \% \mathrm{Cl}$ does not include 1.0).

*Weighted percentage may not add up to $100 \%$ because of rounding. Data weighted to match the sample to the 2012 US Census Bureau's Current Population Survey.

†Frequency of exposure to sports drinks (i.e. Gatorade ${ }^{T M}$ or PowerAde ${ }^{T M}$ ).

¥Frequency of exposure to energy drinks (i.e. Red Bulrm, 5 -h Energy ${ }^{\text {mM }}$, NOS ${ }^{\text {TM }}$ ).

§lncluded each SSB advertising exposure and all sociodemographic variables (i.e. age, sex, race/ethnicity, parent education level, annual family income and geographic region) in one model. Reference category was advertising exposure $<1$ time/week. 
advertising. Further, according to the recent Federal Trade Commission report on food company expenditures on marketing from all types of media exposure (e.g. social media, in-school marketing and in-store), carbonated beverage companies spent more to market their products to teens than any other food category (\$US 382 million), but just $16 \%$ of those expenditures were for television advertising $^{(2)}$. The Rudd Center reported that in 2010, adolescents viewed television advertisements for fruit drinks (i.e. fruit-flavoured drinks), sports drinks and energy drinks averaging $1.9 \mathrm{ads} /$ week, $0.6 \mathrm{ads} /$ week and $2 \cdot 4$ ads/week, respectively ${ }^{(4,6)}$, which is less than what most adolescents reported for these beverages in the present study. However, as with expenditures on carbonated beverage marketing to teens, television advertising represented a lower-than-average proportion (14\%) of marketing expenditures for non-carbonated beverages targeted to teens ${ }^{(2)}$, suggesting that adolescents could be including exposures to other forms of marketing, especially given that exposure to other media outside television is increasing ${ }^{(11)}$.

Our analyses revealed several patterns in self-reported exposure to advertising. First, 14- to 15-year-olds were two to three more likely to report seeing/hearing soda, sports drink and energy drink advertisements than 16- to 17-year-olds. Compared with 16- to 17-year-olds, 14- to 15 -year-olds have been found to more frequently view television for $\geq 4 \mathrm{~h} / \mathrm{d}$ and this may contribute to their exposure $^{(12)}$. Further, using self-reported data, younger teens (11-14 years) had overall greater media exposure compared with older teens (15-18 years) when taking into account exposure to all forms of media, and this increases the likelihood of the younger teens having greater overall advertising exposure to $\mathrm{SSB}^{(11)}$. Second, boys are more likely to report seeing/hearing sports drink advertisements than girls, which could partially be explained by greater awareness of sports drink advertising by boys since boys consume sports drinks more often than females ${ }^{(13)}$. NonHispanic black adolescents were four times more likely to report exposure to both fruit drink and sports drink advertisements compared with non-Hispanic white adolescents. This could be partly explained by non-Hispanic black adolescents having greater media exposure via all types of media than non-Hispanic white adolescents ${ }^{(11,14)}$ and the greater prevalence of food/beverage advertising on non-Hispanic black television ${ }^{(15)}$. Experimental research suggests that African-American consumers respond more favourably to targeted advertising compared with white consumers and have a tendency towards high brand and product loyalty ${ }^{(16)}$; hence, marketers may particularly benefit from targeted marketing to African-American consumers. Further, non-Hispanic black adolescents consume fruit drinks $^{(17,18)}$ and sports drinks ${ }^{(13,18)}$ more often than white adolescents $^{(19)}$, which could suggest heightened awareness of these drinks among non-Hispanic black adolescents. Children of parents with high-school education or less were more likely to report seeing/hearing soda, fruit drink and energy drink advertisements than children of parents who were college graduates, which could be attributed to greater overall media exposure and screen time among children whose parents have lower education levels ${ }^{(11,20)}$.

To our knowledge, our study is the first to report frequency of self-reported overall advertising exposures to SSB by various sociodemographic groups among US adolescents. However, there are a few limitations to the study. First, findings may not be generalizable nationally because of selection bias associated with the use of a convenience sample from an online panel survey with a relatively low response rate. Second, there is a risk of recall errors for self-reported SSB advertising exposure frequency, which, if random, could potentially reduce or eliminate any associations. Further, previous studies have revealed that repeated exposure to advertisements and new youth-targeted marketing techniques (e.g. social media marketing) could undermine the viewer's scepticism and could make adolescents less aware of the marketing intent in digital marketing (e.g. company-sponsored applications and online video games) which they subsequently may not count as exposure to advertising ${ }^{(21)}$. Third, using the present survey, we were unable to determine what types of advertising media contributed to level of self-reported exposure. Fourth, although we were assessing for SSB marketing exposure, it is possible that respondents included diet drinks when reporting for frequency of advertising exposure to Coke, given that the question did not specify limiting responses to regular drinks only. Fifth, given that adolescents were asked to report their exposure to SSB advertisements only, we were unable to determine overall marketing exposure, given that advertising encompasses a narrow definition of marketing. That is, aspects of the features or packaging of an SSB product or the placement of an SSB product in a store was not assessed. Sixth, adolescents who consume a product likely notice more advertisements about the product than adolescents who do not (as has been demonstrated with alcohol), and this could potentially influence our estimates $^{(22)}$. Lastly, with our data set, we were unable to assess influence of SSB advertising exposure on actual behaviours, such as purchase requests or consumption SSB.

\section{Conclusions}

Nearly half of all surveyed adolescents reported seeing/ hearing SSB advertisements once or more times daily. Further, being 14- to 15-years-old, male, non-Hispanic black and having parents with high-school education or less were significantly associated with greater self-reported exposure to advertising of soda, fruit drinks, sports drinks and energy drinks. These results add to the literature base on exposure to SSB marketing among American youth. These data can help inform potential actions that decision makers might take, such as education of adolescents and 
their caregivers on the potential impact of beverage advertising, especially among groups at higher risk for obesity. However, further research may be still needed to determine if overall SSB advertising exposure is linked to actual behaviours, such as purchase requests or consumption of specific beverages.

\section{Acknowledgements}

Acknowledgements: Heidi Blanck, Jennifer Harris and Holly Wethington helped with the creation of the food marketing questions for the HealthStyles survey. Financial support: This research received no specific grant from any funding agency in the public, commercial or not-for-profit sectors. Conflict of interest: None. Disclaimer: The findings and conclusions in this report are those of the authors and do not necessarily represent the official position of the Centers for Disease Control and Prevention. Authorship: G.K. primarily led the development of the research question, analysis and manuscript preparation. S.O. assisted with the development of the research question and manuscript preparation. D.Z. assisted with the analysis and manuscript preparation. B.K. assisted with development of the food marketing questions and manuscript preparation. S.P. assisted with the development of the research question and manuscript preparation. Ethics of buman subject participation: Ethical approval was not required.

\section{References}

1. Powell LM, Szczypka G \& Chaloupka FJ (2007) Adolescent exposure to food advertising on television. Am J Prev Med 33, 4 Suppl, S251-S256.

2. Federal Trade Commission (2013) A review of food marketing to children and adolescents: follow-up report. http://www.ftc. gov/os/2012/12/121221foodmarketingreport.pdf (accessed January 2014).

3. US Department of Agriculture \& US Department of Health and Human Services (2010) Dietary Guidelines for Americans, 2010, 7th ed. Washington, DC: US Government Printing Office; available at http://health.gov/dietaryguidelines/ dga2010/dietaryguidelines2010.pdf.

4. Yale Rudd Center (2012) Trends in television food advertising to young people: 2011 update. http://www.yaleruddcenter. org/resources/upload/docs/what/reports/RuddReport_TVFood Advertising_5.12.pdf (accessed November 2012).

5. Wang YC, Bleich SN \& Gortmaker SL (2008) Increasing caloric contribution from sugar-sweetened beverages and $100 \%$ fruit juices among US children and adolescents, 1988-2004. Pediatrics 121, e1604-e1614.
6. Yale Rudd Center (2010) Sugary drink f.a.c.t.s: Evaluating sugary drink nutrition and marketing to youth. http://www. sugarydrinkfacts.org/resources/SugaryDrinkFACTS_Report.pdf (accessed December 2012).

7. Kit BK, Fakhouri TH, Park S et al. (2013) Trends in sugarsweetened beverage consumption among youth and adults in the United States: 1999-2010. Am J Clin Nutr 98, 180-188.

8. US Census Bureau (2012) Current Population Survey: 2011. http://www.census.gov/acs/www/data_documentation/2011_ release/ (accessed December 2012).

9. Ogden CL, Kit BK, Carroll MD et al. (2011) Consumption of sugar drinks in the United States, 2005-2008. NCHS Data Brief no. 71. http://www.cdc.gov/nchs/data/databriefs/db71.pdf (accessed June 2014).

10. Bleich SN, Wang YC, Wang Y et al. (2009) Increasing consumption of sugar-sweetened beverages among US adults: 1988-1994 to 1999-2004. Am J Clin Nutr 89, 372-381.

11. Kaiser Family Foundation (2010) Generation M2: Media in the lives of 8- to 18-year-olds. http://kff.org/other/event/ generation-m2-media-in-the-lives-of/ (accessed January 2013).

12. Eisenmann JC, Bartee RT \& Wang MQ (2002) Physical activity, TV viewing, and weight in US youth: 1999 Youth Risk Behavior Survey. Obes Res 10, 379-385.

13. Park S, Blanck HM, Sherry B et al. (2012) Factors associated with sugar-sweetened beverage intake among United States high school students. J Nutr 142, 306-312.

14. Powell LM, Szcypka G, Chaloupka JK et al. (2007) Nutritional content of television food advertisements seen by children and adolescents in the United States. Pediatrics 120, 576-583.

15. Powell LM, Szczypka G \& Chaloupka FJ (2010) Trends in exposure to television food advertisements among children and adolescents in the United States. Arch Pediatr Adolesc Med 164, 794-802.

16. Grier SA \& Kumanyika SK (2008) The context of choice: health implications of targeted food and beverage marketing to African Americans. Am J Public Health 98, 1616-1629.

17. Henderson VR \& Kelly B (2005) Food advertising in the age of obesity: content analysis of food advertising on general market and African American television. J Nutr Educ Behav 37, 191-196.

18. Centers for Disease Control and Prevention (2011) Beverage consumption among high school students - United States, 2010. MMWR Morb Mortal Wkly Rep 60, 778-780.

19. African American Collaborative Obesity Research Network (2011) Impact of sugar-sweetened beverage consumption on Black Americans' health http://www.aacorn.org/uploads/ files/AACORNSSBBrief2011.pdf (accessed February 2013).

20. Tandon PS, Zhou C, Sallis JF et al. (2012) Home environment relationships with children's physical activity, sedentary time, and screen time by socioeconomic status. In $J$ Behav Nutr Phys Act 9, 88.

21. Harris JL, Brownell KD \& Bargh JA (2009) The food marketing defense model: integrating psychological research to protect youth and inform public policy. Soc Issues Policy Rev 3, 211-271.

22. Collins RL, Schell T, Ellickson PL et al. (2003) Predictors of beer advertising awareness among eighth graders. Addiction 98, 1297-1306. 